\title{
COLOMBIA: JUSTICIA Y CONFLICTO
}

\author{
Antonio Suárez Niño*
}

\section{A MANERA DE INTRODUCCIÓN}

Los desgarradores hechos ocurridos en los últimos tiempos en Colombia, justifican, en gran medida, la esperanza en la negociación política del conflicto, como la única vía a ensayar; porque se parte de una verdad incontrovertible: la confrontación armada ha demostrado, hasta la saciedad, que no es el paliativo que necesita la sociedad para encontrar salida a los problemas de marginalidad social, ni mucho menos el escenario dentro del cual han de resolverse las controversias ciudadanas. En un contexto enrarecido al máximo por el forcejeo entre quienes añoran una salida básicamente militar al conflicto y aquellos que, desde el otro lado del espectro social y político, pugnan por imponer una salida política negociada, han surgido importantes acontecimientos que hacen pensar en la posibilidad real de las negociaciones entre la insurgencia y el Estado colombiano.

En efecto, los contactos permanentes entre el gobierno actual, por intermedio del Presidente de la República, Andrés Pastrana, y el Alto Comisionado para la Paz, Víctor G. Ricardo, con el Estado Mayor de las Fuerzas Armadas Revolucionarias de Colombia, FARC, han desembocado en la concreción de una agenda para la negociación, que tendría implicaciones en todas las esferas de la vida nacional, porque abarca puntos tan disímiles como la reforma agraria, la composición de las Fuerzas Armadas del Estado, el modelo de desarrollo económico, los poderes legislativo y judicial, la proyección de la política internacional del país, la sustitución de los cultivos ilícitos, entre otros.

Las posibilidades de acercamiento y negociación con el otro grupo insurgente, el Ejército de Liberación Nacional, ELN, en cambio, se han visto enturbiadas por la actitud displicente asumida por el gobierno del presidente Pastrana, que a lo mejor no reconoce en aquel un movimiento capaz de expresarse de una manera tan amplia, desde el punto de vista militar, como las FARC; fenómeno al cual hay que adicionar las sorprendentes e inexplicables accionadas realizadas por el ELN, que, en una clara violación del Derecho Internacional Humanitario, decidió retener a más de un centenar y medio de personas cuando viajaban en un avión hacia la capital de la República, o en el transcurso de un oficio religioso.

En cualquier caso, todo hace pensar en que, de traducirse a la realidad las negociaciones referidas, se estaría
Colombia ubicando en un nuevo escenario político: una reforma constitucional que en la práctica buscaría institucionalizar lo básico de los acuerdos a los cuales se habría llegado con el movimiento insurgente. El momento culminante que vive el país lleva a ensayar nuevas propuestas que, desde la orilla de la democracia, busquen construir nuevos escenarios sobre la base de la ciudadanía, la tolerancia y la coexistencia, en el marco de unos acuerdos cuya validez depende del acompañamiento y el aval de la sociedad civil, como conglomerado que no tiene aspiraciones de asalto al poder, sino la regulación desde el punto de vista ético, del poder político; porque a no dudarlo, el eslabón débil de todas las propuestas de negociación con la insurgencia está dado por la ausencia de esa sociedad civil.

En el fondo, se trata de repensar la política, porque ésta ha de basarse "no en la relación de exclusión e imposición por la fuerza (en el sentido de amigo-enemigo hobessiano y schmittiano), sino en la inclusiva de integración a través de la red de valores y procedimientos comunicativos, que es, además, la única visión no catastrófica de la política posible en nuestro tiempo" (Zagrebelsky, 1997: 14-15). El objetivo de la convivencia en Colombia contiene unas dificultades innegables referidas al estado de confrontación armada y a unas relaciones bélicas entre los ciudadanos cada vez más deterioradas, lo que no ha hecho posible un escenario para civilizar los conflictos.

Es innegable la profunda ilegitimidad del Estado, la cual se manifiesta en un precario dominio territorial, en la incapacidad de generar canales de obediencia entre la población y la imposibilidad de construir una legalidad que garantice el tratamiento adecuado de las controversias ciudadanas, en el contexto de la democracia y el derecho.

Así, el deterioro de los Derechos Humanos arroja unos resultados demenciales: 30.000 muertes violentas en 1997, de las cuales 3439 fueron consecuencia de la violencia sociopolítica; de estos últimos hechos violentos se estima que "el $76 \%$ de ellos son atribuibles a los grupos paramilitares, el $18,6 \%$ a las guerrillas y el $4,4 \%$ a la fuerza pública" ${ }^{\text {. No se }}$ pueden desconocer los estrechos vínculos existentes entre los

* Abogado penalista, especialista en Derechos Humanos. Actualmente, Juez Penal del Circuito de Santafé de Bogotá.

1. Informe de la Alta Comisionada de las Naciones Unidas para los Derechos Humanos en Colombia al 54 periodo de sesiones de la Comisión de Derechos Humanos. Marzo de 1998, pág. 8. 
mencionados grupos paramilitares con sectores de la fuerza pública, pues, según la Oficina de la Alta Comisionada de las Naciones Unidas para los Derechos Humanos en Colombia, se "tiene la percepción de que no pocos de los hechos de violencia perpetrados por los paramilitares se cometen con la tolerancia y, aun, la complicidad de servidores públicos, especialmente de miembros de las fuerzas militares y de la Policía Nacional, como se demostró en el pasado con los casos de Trujillo y Riofrío y como hasta ahora parece demostrarlo el caso de la masacre cometida entre el 15 y el 20 de julio en el municipio de Mapiripán, departamento del Meta” ${ }^{2}$.

La profundización del conflicto ha producido, a su vez, unos efectos arrasadores en el tejido social que hacen que los comportamientos y el lenguaje de la guerra se utilicen en las relaciones cotidianas entre los individuos. Así, la confrontación, como un espiral inexorable, se cuela de manera ascendente en todos los ámbitos de la vida social al ser la definición mecánica de enemigo progresiva, presentándose cada vez menos la necesaria distinción entre el combatiente y el no combatiente.

Este deteriorado proceso indica que la guerra, como confrontación armada entre las guerrillas y la fuerza pública del Estado, es ascendentemente regular y, en ese contexto, debido a la perversión del fenómeno militar, se extiende el carácter de enemigo total a poblaciones y grupos enteros, generándose el desplazamiento interno y forzado de personas que, según cifras de la Consultoría para los Derechos Humanos y el Desplazamiento, CODHES, "cada año asciende a 180.000 personas y el número total de desplazados desde 1985 sería de alrededor de un millón, cifras que coinciden con el análisis de la Defensoría del Pueblo" ${ }^{3}$. Por otra parte, para ahondar en la descomposición del conflicto, todos los días se presenta una mayor presencia de civiles en la confrontación, no sólo mediante su vinculación a las guerrillas o a las llamadas autodefensas, sino a través de su incorporación a los grupos paramilitares y a los llamados "servicios especiales de vigilancia y seguridad privada", conocidos como “Convivir", creados por el Decreto 356 de 1994, las cuales han funcionado sin control y supervisión por parte del Estado, hasta el punto de haber recibido el rechazo de diferentes organizaciones no gubernamentales de defensa de los Derechos Humanos, de ámbitos nacional e internacional; lo que llevó a la Alta Comisionada para los Derechos Humanos en Colombia a recomendar que se pusiese fin a sus actividades, "para facilitar la aplicación del principio humanitario de distinción en el conflicto armado, y para que el Estado pueda tener, en todo tiempo y circunstancia, control absoluto sobre la aplicación de la fuerza y el uso de las armas" ${ }^{4}$.

En este marco debe actuar la justicia colombiana. Las siguientes reflexiones apuntarán a ubicar su realidad, lacerante como el país al que pertenece. Con una advertencia: obedecen a un análisis que, desde el punto de vista progresista, concibe que la razón de ser del Poder Judicial es buscar la garantía de los Derechos Humanos.

\section{UNA JUSTICIA DÉBIL Y EXCEPCIONAL}

El examen de las diferentes crisis que hacen imposible la convivencia social, en términos más o menos estables y democráticos, contiene el sustrato y el sobredimensionamiento de lo jurídico, consistente en reducir todo a un mero sustento legal, para cambiar la realidad como por arte de magia. Por eso, en Colombia hay un eterno retorno al reformismo institucional, inspirado en que bastan nuevas normas para enfrentar situaciones extremas, que desde luego esperan soluciones en esferas diferentes de la jurídica, como la económica o la política.

La función de administrar justicia, así, tiene connotaciones contradictorias, caracterizadas por:

a) La intervención "excepcional" del poder judicial en asuntos cuyo conocimiento residía en otros ámbitos, en un proceso conocido ampliamente como de “judicialización de la política”, en el que se vieron afectados conspicuos exponentes de los sectores gubernamentales; entre ellos, el anterior Presidente de la República, a la postre favorecido por una decisión exculpatoria y controvertida de sus "jueces naturales”, los 109 miembros de la Cámara de Representantes (Congreso de la República), quienes posteriormente fueron investigados por este hecho, presuntamente constitutivo de prevaricación, o cohecho.

De tal manera, amplios sectores de la sociedad vieron en el Poder Judicial y, concretamente, en la Fiscalía General de la Nación (que según el artículo 249 de la Constitución Nacional, hace parte del Poder Judicial) y en la Sala Penal de la Corte Suprema de Justicia, los únicos escenarios posibles no sólo para adelantar el procesamiento de personas vinculadas a las elites en el poder -lo cual, obviamente es una obligación constitucional y legal- sino para buscar un cambio en las costumbres políticas, dirigido a expulsar a los miembros del Congreso, cuyo desprestigio crece cada vez más. Los efectos, desde el punto de vista democrático, fueron perversos, pues no se dio el consenso ciudadano, en la medida en que la solución a los conflictos pasaba por la actividad de jueces y fiscales providenciales. Con esta lógica, que desafortunadamente corresponde a los hechos y la realidad, los representantes de origen popular son corruptos y es el poder judicial el que restaura la moral. Ello puede llevar a preguntarse para qué sirve la democracia, en un cuestionamiento de profunda estirpe autoritaria.

b) La incapacidad del Poder Judicial para responder a los requerimientos de justicia material, provenientes de los conflictos sociales.

El círculo vicioso, según el cual la violencia genera impunidad, o ésta produce aquella, está construido sobre una legalidad tercamente ilegítima. El Poder Judicial, a pesar de su relativa renovación con la Constitución de 1991, ha sido incapaz de cumplir su papel de garante de los Derechos Fundamentales y de escenario de resolución de los conflictos ciudadanos por la vía de la civilidad.

La política judicial, en los últimos años, ha sido errática y contradictoria al mismo tiempo, pues, de una parte, se

2. Op.cit., pag. 10. Recientemente, con ocasión de la investigación por la masacre de campesinos en Mapiripán, acusados de auxiliar o pertenecer a las FARC, se dictó auto de detención, con captura, en contra del General del Ejército, Jaime Alberto Uscátegui.

3. Op.cit., pág. 21.

4. Op. cit., pág. 43 
asistió a la criminalización de determinados comportamientos sociales, con evidentes restricciones de las garantías procesales, a través de la expedición de la Ley de Seguridad Ciudadana (cuyos "clientes", para utilizar un lenguaje eficientista, son los sectores sociales violentamente sustraídos del aparato productivo y desconocidos por la producción nacional, a quienes no llega la cobertura de salud, educación, nutrición y empleo) y, de otro lado, sobrevivieron las "jurisdicciones especiales" de Orden Público (sin rostro) y Penal Militar. Que son, la primera, un abigarrado conjunto de normas desconocedoras del debido proceso, del acceso a la justicia, del juez natural, la contradicción de la prueba y el juicio público, que han conducido en no pocas ocasiones a la criminalización de la protesta social, como aconteció con motivo de conflictos laborales en los sectores de las telecomunicaciones y los hidrocarburos; y la segunda, la cobertura legal con que cuentan los miembros de la fuerza pública para que sus comportamientos delictivos, que afectan los Derechos Humanos, queden en la impunidad.

c) De otra parte, en contraste con lo anterior, se ha estructurado un importante proceso de constitucionalización de los Derechos Humanos, a partir de la expedición de la Carta Política de 1991, creadora de una serie de mecanismos de protección de los mismos, como las acciones de tutela (o acciones de amparo), de cumplimiento y populares, así como la elevación a canon constitucional del Hábeas Corpus y el debido proceso.

En las condiciones anotadas, fluctuantes entre el uso simbólico del derecho, que bajo un pretendido enfrentamiento de la criminalidad propicia salidas conculcatorias de las garantías ciudadanas y un tibio proceso de protección de los Derechos Fundamentales, la "aplicación extraterritorial del derecho", según la expresión gráfica del mexicano Jorge Castañeda (1994), se ha obstaculizado, en gran medida, en Colombia, la posibilidad de formulación de una política criminal coherente. En efecto, las presiones internacionales provenientes de los Estados Unidos, para que fuera restablecida la extradición de delincuentes colombianos a ese país, la certificación anual de "buen comportamiento" al Estado colombiano por su batalla contra el narcotráfico y, en general, las diversas posiciones asumidas frente a este fenómeno, han contribuido a la inexistencia de una estrategia transparente de confrontación del delito y de los delincuentes, ya que en el caso específico de los cárteles de la droga se ha oscilado entre la represión directa (política de erradicación de cultivos y fumigación de amplias zonas rurales del país, con los resultados de desbarajuste ambiental que el hecho implica) y la negociación (política de sometimiento a la justicia e ingreso de dineros provenientes del narcotráfico a las campañas políticas).

\section{Las "otras justicias"}

La crisis de legitimidad del Estado colombiano tiene sus manifestaciones en los diferentes comportamientos que asume, de acuerdo con el contexto en que se desenvuelve. Así, en territorios previamente señalados como de alto conflicto, su accionar es ante todo represivo, con una asfixiante presencia de la fuerza pública, lo cual crea las condicio- nes para la concurrencia de comportamientos transgresores de los Derechos Humanos.

Por otra parte, la ausencia del Estado en algunas regiones del país posibilita el surgimiento y consolidación de grupos mal llamados de "justicia privada". Tales grupos -paramilitares y milicias- actúan debido a la ausencia del poder mediador del Estado y ante la necesidad de establecer ciertas normas mínimas, que sólo pueden garantizar mediante el uso de la fuerza. La "justicia sumaria" que establecen y desarrollan arroja unos altos índices de "eficacia" en cuanto que sus resultados son inmediatos, originando con frecuencia la irrupción de verdaderos "justicieros" a los cuales pueden acudir (por ejemplo, el sicariato y los matones a sueldo) los ciudadanos para buscar salidas a sus litigios, sin obstáculos, ni "formalismos legales".

\section{La justicia de excepción}

Es verdad que la mayor conflictividad social no encuentra, en la actividad de la justicia, salidas que garanticen soluciones eficaces. Para enfrentar los hechos que implican conflicto penal, por ejemplo, se ha acudido de manera inveterada a las fórmulas excepcionales que agravan, cada vez más, la crisis de legitimidad de la justicia. Sus efectos son evidentes:

a) Desbordamiento de la justicia penal de excepción, proyectada para el llamado restablecimiento del orden público. Se ha estructurado un ordenamiento punitivo que conlleva la ampliación de los poderes de policía con menoscabo del control judicial. En el caso colombiano, el fenómeno se observa con la atribución de amplias facultades a los cuerpos de seguridad del Estado, para recolectar pruebas iniciales en aquellos lugares en los cuales, presumiblemente, se cometen delitos relacionados con las llamadas "zonas de orden público".

Al mismo tiempo, se restringen algunas garantías a los imputados, lo cual implica la inexistencia de juicios públicos, la ausencia de la presunción de inocencia, la falta de contradicción de las pruebas incriminatorias y la imposibilidad del procesado de recusar a quien investiga o juzga su conducta.

Todo lo anterior derivó rápidamente en tribunales especiales de juzgamiento de determinados comportamientos, ya sean penales militares o de orden público (la llamada justicia sin rostro), los cuales fueron creados para perseguir conductas delictivas que atenten contra el orden económico y social y la Seguridad del Estado, es decir, aquellas referidas al narcotráfico y al terrorismo, con una clara perversión en este último caso: la liquidación del delito político, en un proceso absurdo de negación del móvil insurgente. Finalmente, se acudió al deslizamiento del derecho penal del hecho al derecho penal del reo y a "especialidades en el derecho penal sustantivo, caracterizadas por un incremento de las penas" (Giménez García, 1997), en un contrastante proceso de configuración simbólica del derecho, en virtud del cual, ante comportamientos con un gran impacto dentro de la sociedad, lo mejor era incrementar la dosimetría penal, para crear en aquella, la falsa sensación de eficiencia.

b) Ante el crecimiento de la demanda social de justicia, lo excepcional de torna en permanente, pero sin encontrar 
solución viable, de ninguna manera, al ascendente estado de conflictividad.

La demanda social de justicia no encontró entonces respuestas en la institucionalidad que, lejos de colocarse a la altura de las exigencias, estructura una "cultura de la excepción constitucional", sustento indudable de dos formas de violencia: las violaciones de los Derechos Humanos, cometidas por agentes estatales y la creación de grupos armados que ejercen "justicia privada", algunos de ellos legalizados a través de las llamadas asociaciones de seguridad, "convivir". Los efectos inmediatos son claramente advertibles: a mayor crecimiento del aparato represivo, mayores índices de delincuencia y, a su vez, ascenso del conflicto.

\section{EL CONFLICTO Y LA JUSTICIA}

Se ha sostenido que para enfrentar el conflicto armado, desde el punto de vista de la justicia, se han ensayado dos fórmulas: la jurisdicción especial de orden público y la penal militar, que hizo crisis en los últimos años, alcanzando unos niveles tales de ilegalidad, que a partir de 1991, por disposición constitucional, ningún particular puede ser juzgado por los tribunales castrenses, fuera de que, según reciente pronunciamiento de la Corte Constitucional, el fuero militar no está referido a los delitos de lesa humanidad.

En los dos casos referidos, se trata de tribunales o juzgados de excepción, no sólo por estar de esa manera concebidos en las normas procedimentales, sino porque sus magistrados y jueces no son escogidos por el sistema de carrera judicial, pues, en su designación priman los criterios de libre nombramiento y remoción; desde el punto de vista instrumental, se aplican estatutos diferentes de los generales, lo que conlleva la reducción de las garantías dentro del proceso penal: jueces y testigos sin firma, inexistencia de juicio público y de los principios de contradicción, publicidad e inocencia y, en lo que respecta a su competencia, se abarcan determinados comportamientos distintos de los contenidos en las normas penales generales, como el terrorismo, el lavado de activos y el narcotráfico.

Se torna el escenario del derecho penal, muchas veces, en instrumento de guerra $y$, en esa medida, se establecen ordenamientos en contravía de los Derechos Humanos. Se estructura un nuevo escenario de la "guerra punitiva": la guerra judicializada, que lleva a la guerrerización de la justicia, como instrumento de la confrontación ${ }^{5}$, que en el caso colombiano está claramente referida en las normas sustantivas y procesales de la jurisdicción de orden público que, desde el punto de vista general, se ha convertido en el mecanismo permanente por excelencia de la política criminal frente al conflicto armado.

Según el mandato de la Ley Estatutaria de la Administración de Justicia la jurisdicción de orden público debía cesar sus efectos a partir del primero de julio de 1999, un nuevo proyecto, presentado por el Fiscal General de la Nación, busca revivir, en lo fundamental, sus aspectos controvertidos: fiscales sin rostro, testigos secretos y competencia de instrucción respecto de los delitos de narcotráfico a gran escala, terrorismo, enriquecimiento ilícito y secues- tro. Lo anterior, no sólo constituye un contrasentido en términos de posibilidades de airear por la vía de la democracia y del Estado Social de Derecho el Poder Judicial, sino una inconsecuencia en el ámbito del comportamiento del actual gobierno que, al mismo tiempo busca escenarios para negociar con el movimiento insurgente, pero desconoce la realidad de las violaciones sistemáticas de los Derechos Humanos, por parte de esta jurisdicción especial. En tal dirección, los sectores parlamentarios que apoyan al actual gobierno han dado muestras fehacientes de apoyo a la iniciativa de perpetuación de esta jurisdicción especial, que en la actualidad es materia de debate en el Parlamento. En cualquier caso, todo lleva a pensar que, nuevamente, se estará ante el fortalecimiento de un aparato excepcional de justicia, porque así lo demuestra el actual debate en el Congreso de la República, prueba de lo cual es la reciente renuncia del Ministro de Justicia, Parmenio Cuéllar, quien públicamente criticó el apoyo dado por la actual administración del Estado al referido proyecto.

En el caso de la jurisdicción penal militar, el proceso ha sido claramente revelador: las investigaciones en las cuales pueden resultar afectados miembros de la fuerza pública son eludidas o distorsionadas, dando paso a la impunidad. No es esta una característica exclusiva del comportamiento de los tribunales castrenses, en tanto bajo una antidemocrática percepción de la solidaridad de cuerpo optan por absolver o archivar a quienes resulten imputados por acciones delictivas. La justicia ordinaria o civil aporta su dosis de extravagancia, pues, la Sala Jurisdiccional Disciplinaria del Consejo Superior de la Judicatura -que, según mandato constitucional, dirime los conflictos de competencia que se suscitan entre las distintas jurisdicciones-, ante casos demostrados de violación de los Derechos Humanos por parte de integrantes de la fuerza pública, ha decidido otorgar competencia para conocer de los mismos a la justicia castrense, en algunas ocasiones, desconociendo inclusive lo resuelto por la Corte Constitucional acerca del alcance del fuero militar, pues, según ésta, "un delito de lesa humanidad es tan extraño a la función constitucional de la fuerza pública que no puede jamás tener relación con actos propios del servicio, ya que la sola comisión de esos hechos delictivos disuelve cualquier vínculo entre la conducta del agente y la función propiamente militar o policial, por lo cual sus conocimientos corresponden a la justicia ordinaria" ".

Un factor adicional de perturbación está dado por la desprotección en que se hallan los operadores de justicia, lo cual es crítico en aquellas zonas en donde hay una mayor intensidad del conflicto armado. Las constantes amenazas contra su integridad personal son respondidas con la heroica persecución de los responsables de los delitos o con la omisión de la actividad jurisdiccional, pues, a la larga, no se cuenta con el respaldo de las demás instituciones estatales

5. Sobre estos conceptos, es importante analizar el estudio reciente realizado por OROZCO ABAD, Iván y GÓMEZ AlBARELlO, Juan Gabriel (1997). En Los peligros del constitucionalismo en materia criminal. Santafé de Bogotá: Ministerio de Justicia y del Derecho.

6. Corte Constitucional de Colombia. Sentencia C 358 de 1997. Magistrado Ponente, Eduardo Cifuentes Muñoz. Pág. 37. 
y, en algunas oportunidades, son inclusive víctimas de la acción u omisión de los miembros de la fuerza pública. La situación descrita ha generado asesinatos, masacres, desapariciones y exilio: en 16 años 392 operadores judiciales fueron asesinados, con una media de dos muertes violentas por mes, 12 jueces, fiscales y funcionarios debieron abandonar el país, 14 han sido desaparecidos y los restantes han muerto por la acción de grupos paramilitares (que actúan en territorios controlados por la fuerza pública), guerrilleros y sicarios. En la actualidad, cuatro fiscales y jueces se hallan en poder de los dos grupos insurgentes más importantes del país, el E. L. N. y las F. A. R. C., en una clara muestra de violación de las normas del Derecho Internacional Humanitario, al concebirse al Poder Judicial como objetivo militar por parte de algunos actores armados, en aquellas zonas en las que la confrontación presenta preocupantes niveles de ascenso y descomposición.

\section{LA RECONSTRUCCIÓN DE LA JUSTICIA EN COLOMBIA}

En una sociedad democrática, los conflictos han de solucionarse a través de la ley, expedida con el concurso de la ciudadanía, en un diáfano proceso de respeto y tolerancia y, antes que ello, los ciudadanos, conscientemente, han de someterse al arbitraje de la ley, en cuanto es una manera de replantear, si se quiere, el aparato de justicia. Punto central en el contexto de eventuales negociaciones o salidas políticas consensuadas al conflicto armado en Colombia es el tema de la justicia, como elemento civilizador de sometimiento de los ciudadanos a la juridicidad.

Se trata, entonces, de recomponer la justicia a partir de la ciudadanía, pues, "parece que la racionalidad de la justicia y el sentimiento de pertenencia a una comunidad han de ir a la par, si deseamos asegurar ciudadanos plenos y a la vez una democracia sostenible" (Cortina, 1997: 34). Es necesaria una administración de justicia capaz de enfrentar las tendencias autoritarias del Estado, contribuir a frenar la corrupción, derrotar la impunidad y erigirse en escenario propicio para dirimir los conflictos, con un fondo irrestricto de garante de los Derechos Humanos; es decir, una justicia democrática. Lo que conlleva en la realidad colombiana:

a) Elaboración y consolidación de una política judicial para la paz, con la participación ciudadana, lo cual implica una reforma integral de la justicia inspirada en el acceso democrático a ésta, el respeto de las garantías y Derechos Humanos y de la independencia judicial.

Esta política debe ubicar al Poder Judicial en el centro garantizador de los Derechos Humanos. Para derrotar la impunidad con respecto de los crímenes de lesa humanidad (genocidio, desaparición forzada, tortura, graves violaciones al Derecho Internacional Humanitario) ha de configurarse una política criminal que privilegie los mecanismos de la verdad, la justicia y la reparación de las víctimas.

b) El desarrollo efectivo de los mecanismos alternativos de solución de conflictos, creados en la Constitución de 1991, en un marco de preservación del carácter público de la justicia judicial, es decir, la implementación de instrumentos a los cuales no puede llegar la acción democrática de la justicia institucional.

c) Reformulación del papel del Poder Judicial en el Estado de Derecho, para exigir la plena responsabilidad del juez en su labor cotidiana, lo que conlleva una formación en la cultura de los Derechos Humanos, la concepción de la justicia como servicio público a favor de los ciudadanos y el compromiso estatal de proteger el derecho a la vida e integridad personal de los operadores judiciales.

d) Diseño de una política criminal que vuelva los ojos hacia el Derecho Internacional Humanitario, "como derecho mínimo de los Derechos Humanos, que debe ser respetado aún en circunstancias de conflicto armado no internacional, en cuanto eje normativo-constitucional, para que hagamos de él criterio central en el diseño de las grandes políticas de Estado en materia de seguridad y en parte también en materia criminal" (Orozco y Gómez, 1997: 429).

Ese diseño implica, como es obvio, de una parte, la autonomía del Estado colombiano para fijar su política criminal, sin interferencias externas que favorezcan la implantación de ordenamientos unilaterales, como base propiciatoria para la creación de jurisdicciones especiales; y, de otra parte, el desmonte de éstas y, ante todo, de la llamada "justicia sin rostro" o de orden público, por desconocer las garantías procesales y los Derechos Humanos.

De igual manera, es indispensable limitar el fuero mili$\operatorname{tar}$ (han sido escandalosas algunas decisiones tomadas por la Sala Jurisdiccional Disciplinaria del Consejo Superior de la Judicatura, en lo referente a la preservación del fuero militar. El más significativo de ellos es el relativo al general retirado Farouk Yanine Díaz, investigado por la Fiscalía por la conformación de grupos paramilitares en el Magdalena Medio y por su participación en varios hechos de sangre, actos que la mayoría de esa Sala consideró como realizados en relación con el servicio. Se privó a la Fiscalía de la posibilidad de seguir investigándolos y se entregó la competencia, para ello, a la Jurisdicción Penal Militar, cuyo máximo Comandante, el entonces Presidente del Tribunal Superior Militar, general Harold Bedoya Pizarro, era quien había planteado el choque de competencias, y que en varias ocasiones se pronunció a favor del general Yanine, comparándole con los héroes de la independencia Bolívar, Santander y Córdoba. En la actualidad, merece profunda atención la demanda castrense para que el proceso por los sucesos de Mapiripán pase a la jurisdicción penal militar quien, según su criterio, debe conocer la investigación adelantada contra el General Uzcátegui, uno de los principales implicados en el asunto) teniendo como referencia la aludida sentencia de la Corte Constitucional, en cuanto que los delitos contra la humanidad no pueden ser conocidos por la Justicia Penal Militar, sino por la ordinaria o civil, con miras a avanzar en la derrota de la impunidad en esos niveles e ir proyectando el contenido de la reparación de las víctimas.

En síntesis, se trata de repensar y reconstruir el servicio público de la justicia dentro de un Estado que tenga como marco de referencia el respeto de los Derechos Humanos y el fortalecimiento democrático. Así de grande es el compromiso. Así de fascinante y necesario. 